\title{
"Brincar de osadia": sexualidade e socialização infanto-juvenil no universo de classes populares
}

\author{
"Sex-daring games": sexuality and gender \\ socialization in the working-class children's universe
}

\footnotetext{
${ }^{1}$ Departamento de Ciências Humanas e Filosofia, Universidade Estadual de Feira de Santana. Km 3, BR 116 ,

Campus Universitário Feira de Santana, BA 44031-460, Brasil. jucelia@ufba.br
}

\begin{abstract}
This article focuses on the socialization of children and youth with respect to gender and sexuality, from a socio-anthropological perspective. The work is based on ethnographic research in a group of 5-14-year-old boys and girls in a community in Baia de Todos os Santos, Bahia, Brazil. Despite the strong influence of family and school in primary socialization, the children reproduced and re-elaborated norms and practices on appropriate gender and sexual conduct, especially among their peers, and primarily in the context of play. The research analyzes the children's representations and practices in this socializing process, showing how gender and sexuality are socially constructed according to the contexts in which the different social interactions take place.
\end{abstract}

Key words Sexuality; Gender; Socialization; Childhood

Resumo Este artigo focaliza o processo de socialização infanto-juvenil no que diz respeito ao gênero e sexualidade, a partir de uma perspectiva sócio-antropológica. O trabalho baseia-se em pesquisa de cunho etnográfico, que teve como alvo grupos de crianças de ambos os sexos, dos 5 aos 14 anos de idade, pertencentes a famílias das camadas populares de uma comunidade na Baía de Todos os Santos, Bahia, Brasil. O estudo mostrou que, apesar da forte influência da família e da escola na socialização primária, as crianças reproduzem e reelaboram representações sobre gênero e conduta sexual adequada, sobretudo com seus pares, principalmente no contexto de diferentes brincadeiras infantis. A pesquisa analisa as representações e as práticas dos grupos observados nesse processo socializador, revelando como gênero e sexualidade são construídos socialmente, dependendo dos contextos em que se dão as diferentes interações sociais.

Palavras-chave Sexualidade; Gênero; Socialização; Infância 


\section{Introdução}

Este artigo é resultante de uma pesquisa etnográfica sobre o processo de socialização em que a sexualidade e os padrões de gênero são reproduzidos e construídos cotidianamente entre crianças, em Pinaúna (este nome, assim como de todos os entrevistados(as) são fictícios), comunidade de uma ilha na Baía de Todos os Santos, na região do Recôncavo Bahiano. Interessada em conhecer as práticas e representações infantis na construção da sexualidade, e a socialização em relação ao gênero no período que precede a entrada na vida sexual e reprodutiva, procurei trabalhar com crianças de maior domínio da linguagem falada, centrando em diferentes grupos que variam de 5 a 14 anos de idade, decisão tomada devido à forma como as próprias crianças se agrupam na comunidade: separam-se por sexo, sempre em grupos de cinco a sete anos de idade, e de oito a treze ou quatorze anos. Foram privilegiados dois espaços para as observações: uma escola pública de ensino fundamental e um espaço de sociabilidade infantil como a praia. O intuito foi contrastar as concepções e práticas com a sexualidade em diferentes contextos sociais: um institucionalizado e outro mais livre dos constrangimentos disciplinadores dos adultos.

Por meio desta etnografia, mostrarei que a sexualidade é construída socialmente e como ela é apreendida pelas crianças em vários contextos sociais, como a escola e a família, pelos meios de comunicação, nos livros e principalmente com os colegas e amigos. Meu argumento é que, adultos e crianças têm representações diversas, contraditórias e às vezes opostas sobre a sexualidade, sendo veiculadas ora em seu sentido normativo e medicalizante (biologização), ora como fantasia, brincadeira e "sacanagem".

Para a análise deste tema do comportamento sexual e socialização, a abordagem antropológica tem fornecido muitas contribuições, como nos estudos clássicos quando a sexualidade passou a ser reconhecida como construção social, efeito dos padrões culturais. A psicologia freudiana teve influência destacada nessa linha de pesquisa e sob a teoria da cognição e da sexualidade, o período da primeira infância foi evidenciado como momento significativo para o aprendizado comportamental. Nessa tradição de pesquisas etnográficas em sociedades ditas "primitivas”, a Antropologia debateu as teorias psicobiológicas do comportamento humano, rejeitando ou criticando o essencialismo no discurso da sexualidade (Malinowski, 1982; Mead, 1971). Nesses estudos, os pesquisadores se interessaram em entender como meninas e meninos adquirem os chamados “papéis sexuais", em diferentes contextos sócio-culturais.

Com perspectivas diversas, as investigações recentes mostram a importância de se retomar essa discussão, sobretudo em se tratando da construção social da sexualidade e de gênero (Corrêa, 1994; Epstein, 1999; Schieffelin, 1990), assim como a socialização em pares com base no universo infanto-juvenil. A literatura das últimas décadas tem seguido algumas abordagens específicas, duas delas mais conhecidas: uma essencialista e outra conhecida por construtivista social, a qual tem destaque neste trabalho. O essencialismo permanece trabalhando com as idéias de uma natureza sexual universal e as diferenças marcadas pelo aparato biológico, enquanto o construtivismo relativiza essas noções, problematizando os significados atribuídos ao corpo e ao sexo em culturas ou grupos específicos (Heilborn, 1999; Loyola, 1999). Nesta última, em sentido mais geral, sexualidade é compreendida como construção social e histórica da experiência sexual pelos processos subjetivos e simbólicos na percepção do corpo e suas práticas (Heilborn, 1999; Parker, 1991; Weeks, 1999).

Uma outra questão a ser considerada é que, no discurso das pessoas adultas como as docentes desta pesquisa, está a idéia de que a criança não se interessa pela sexualidade, e que ela só adquire conhecimentos sobre questões sexuais por intermédio da família e escola. Não sem contradições, as professoras acreditam numa infância inocente, onde a sexualidade está ausente e que os jovens, nessas idades, não aprendem sobre eroticidade, intimidades do corpo e dos relacionamentos afetivos de outra forma que não seja pelos agentes socializadores credenciados, tais como os pais e o próprio professorado.

No entanto, como veremos, em Pinaúna as crianças elaboram idéias sobre as relações sociais de sexo em seu meio, atuam umas sobre as outras como agentes socializadores e delimitam os espaços simbólicos de convivência próprios aos homens e às mulheres. Nas interações cotidianas no meio infantil, os atores sociais apresentam classificações que atendem aos tipos ideais na definição do que seja o comportamento adequado de meninos e meninas. Demonstrarei então, como essas crianças reproduzem as informações transmitidas pelos adultos, e reelaboram formas de classificação sobre a maneira de ser e agir das pessoas com quem dialogam e convivem, iniciando um ciclo em que as primeiras construções sociais so- 
bre sexo e gênero se evidenciam nas formas simbólicas de gestos, palavras consideradas obscenas, brincadeiras de erotização do corpo, apreendidos entre os pares da socialização.

\section{O trabalho de campo e a comunidade}

Realizei o trabalho de campo num período de três meses, de outubro a dezembro de 2001 , com observação direta na comunidade e também com visitas esporádicas antes e depois desse período, em diferentes dias da semana. Por meio de roteiro semi-estruturado, fiz entrevistas com 11 professoras, alguns meninos e meninas de forma individual (18 crianças) e na maioria das vezes com grupos de crianças de 5 a 14 anos de idade. Essa estratégia deveu-se ao fato de as crianças terem maior motivação para falar do corpo e da sexualidade estando em grupo, quando começam as divergências ou pilhérias entre amigos(as).

A minha inserção em campo deu-se mediante o conhecimento prévio de algumas pessoas do lugar, inclusive uma velha amiga, atualmente professora das séries iniciais (ensino fundamental) da comunidade, a qual viabilizou minha hospedagem numa casa de uma família do lugar. Essa moradia temporária no campo possibilitou-me uma experiência ímpar, uma vez que algumas observações feitas na escola e na "rua" sobre crianças e adultos eram complementadas no convívio cotidiano com as pessoas da comunidade. Em dias diferentes da semana eram feitas visitas à escola nos turnos da manhã e tarde, e à noite na pracinha (as crianças também brincam nesse espaço, das 6:00 às 22:00, aproximadamente). Nos finais de semana e feriados privilegiava as observações e conversas na praia.

No começo, encontrei dificuldades de várias ordens, pois as crianças e também os pais me olhavam com desconfianças e me evitavam como a uma "estranha". Esses estranhamentos iniciais me fizeram buscar alternativas na escola, já que eu tinha permissão das professoras para fazer as observações durante o recreio. Essa estratégia foi bastante eficaz, pois a meninada passou a interagir cotidianamente comigo, e as mães, ao saberem das minhas idas à escola, deixaram de me "fiscalizar" nos momentos em que conversava informalmente com meninos e meninas na rua e na praia. As crianças, por sua vez, como não entendiam muito bem o trabalho, ora pensavam que eu era a professo$r a$, ora a moça da entrevista e por vezes imaginavam que iam aparecer na TV, gritando de quando em vez: "eu vou passar no jornal!".
Por se tratar de tema bastante delicado, o período de coleta das informações por meio de entrevistas só foi iniciado após sujeição da pesquisa ao Comitê de Ética do Hospital Universitário Professor Edgar Santos (HUPES) da Universidade Federal da Bahia (UFBA) e anuência dos pais e professores mediante assinatura de consentimento informado.

Como características gerais, a comunidade é constituída por uma população majoritariamente negra, de baixíssimo poder aquisitivo, sendo que as pessoas têm a situação de pobreza minorada pela atividade pesqueira e pelos vínculos familiares nos laços de parentesco, em ajudas mútuas, apesar das extremas carências materiais na baixa estação, período que compreende os meses de abril a novembro (ciclo de calmaria no fluxo turístico e refluxo da população flutuante em veraneio).

A praia e a freqüência aos bares são as atividades de lazer mais comuns às pessoas do lugar, principalmente para os homens, ainda que vários grupos de mulheres compartilhem esses espaços. Entre as crianças, a sociabilidade é intensamente vivida também na praia (mais comum aos meninos) e numa pracinha. Durante a semana, com a maré cheia, vários grupos de meninos e algumas poucas meninas pescam siris em jererés ou jogam tarrafas para a pesca de pequenos peixes. Todo final de tarde e nos finais de semana são organizados grupos para o jogo de futebol na praia, normalmente separados por grupos de idades: os jogos com bola das crianças, os times dos jovens-adolescentes e o "baba" dos homens-adultos. A praia (também a praça) e a escola, portanto, são espaços significativos para uma análise das construções de gênero infanto-juvenis nesse contexto social.

\section{Da porta da sala: \\ as sexualidades no pátio da escola}

A escola onde foram feitas as observações é dividida em quatro salas de aula, funcionando nos turnos da manhã e da tarde entre as séries da prontidão e quarta do ensino fundamental. Todas as salas ficam com a porta virada para o pátio, área sem cobertura, chão de areia, onde a criançada brinca no horário de recreação. Nesse espaço da sociabilidade, os usos do corpo ganham conotações envolvendo a sexualidade de forma explícita nas preocupações das docentes e nas brincadeiras de meninos e meninas. Sobre uma turma, uma professora comenta: "já tinha esses namoros e eu ficava de olho; na hora do recreio as meninas inventavam desculpas pra não brincar; alguma menina re- 
cebeu um beijo no rosto, aí já dizia que namorava; quando alguma criança via ia dizer à professora" (Jurema, professora). Numa outra ocasião, outra docente tece um comentário, indignada com a "falta de educação doméstica" e "osadia" dos garotos: "a última que me aprontaram, tentaram tirar a calça do menino".

Da porta da sala, as professoras vigiam os alunos, atentas para os sinais de eroticidade, algumas vezes só percebidos com a denúncia das próprias crianças. Segundo Louro (1997), a escola é também o lugar de controle sobre a linguagem e comportamento sexual das pessoas, de forma a produzir e reproduzir corpos dessexualizados e disciplinados. No entanto, nem sempre a vigilância dos adultos ou colegas é eficaz, para felicidade das crianças. Alguns momentos são aproveitados para brincar com o corpo e suas significações e estabelecerem os códigos sexuais conhecidos no grupo, como a brincadeira de pegar nas nádegas, feita entre os meninos mais velhos (a partir dos sete anos): beliscam as nádegas dos colegas que estão sentados ou, em pé, encostam a virilha naquele que está situado à frente, como nas horas em que fazem filas indianas. As "vítimas" se espicham para a frente e para o lado, reclamam bastante, pois são colocados simbolicamente como sujeitos passivos, motivo de galhofas e gargalhadas.

Ainda nesse âmbito escolar, as meninas procuram se aproximar das representações das professoras ao naturalizarem a conduta masculina em relação à agressividade, ao desinteresse pelo estudo e o interesse pela eroticidade, já que "esses meninos (da escola) são malvados, gostam de bater", e "as meninas brincam de roda e os meninos abusam, brincam de luta", além de que, "os meninos não fazem os deveres na sala” (Renata, 9 anos); "xingam porra, não prestam atenção no dever, bagunçam na sala" (Rosinha, 10 anos). Nesses e outros exemplos, aqueles meninos que gostam de brincar duelando com o corpo dos colegas, os que são violentos física e verbalmente e os mais relaxados nas tarefas escolares são aqueles caracteristicamente associados ao tipo de menino "osado". Uma garota afirma que: "os meninos ficam abusando as meninas. A professora diz que os meninos de treze anos só querem namorar. Os meninos ficam fazendo osadia na escola. Um menino da sala escreveu uma carta para Vanessa dizendo que o menino de treze anos (o mais velho da turma) só queria a piriquitinha (vagina) dela, a piriquitinha gorda de Vanessa" (Iasmina, 10 anos).

Nas falas de professoras e alunas, os meninos são colocados como os mais precoces no interesse pelo namoro, ainda que entre as crianças elas separem aqueles meninos que querem namorar simplesmente e os "osados", que querem apenas sexo. Há também uma tendência geral no discurso das meninas a identificar os meninos como os mais interessados pela sexualidade, pois segundo muitas delas, eles "aprendem osadia pela rua e com os irmãos mais velhos". Entretanto, os garotos denunciam a não inocência das garotas, pois, segundo eles, "as meninas ficam assim, dando dedos pros outros" (vários deles fazem o gesto considerado obsceno, mostrando o dedo médio empunhado para cima, com os demais fechados).

Para contrastar o comportamento masculino da conduta feminina adequada, as garotam ressaltam que "tem bom comportamento aquela menina que não xinga, não dá osadia aos meninos" (Iasmina, 10 anos). "As que têm mau comportamento, batem nas pessoas fracas, procuram osadia com os meninos. Exemplo: senta ali no banco (da praça), dá risada pros meninos quando eles ficam piscando o olho" (Jamira, 8 anos). Já nas atitudes dos meninos, generaliza-se o comportamento "osado", pois: "as meninas se abaixam pra pegar alguma coisa no chão e os meninos ficam roçando na bunda, com osadia" (Andréa, 8 anos). "Também na sala (escola) tem um menino que bota o lápis dentro do short, pra dizer que é o negócio (simula um pênis ereto sob a roupa) dele" (Jamira, 8 anos). "Os meninos são osados, ficam chamando as meninas pra ir pro beco. Os meninos da praça, não tem um menino que não chame a menina de gostosa, de bonita" (Iasmina, 10 anos). Nesses discursos, a “osadia” parece estar presente como uma marca exclusiva de masculinidade, mas também há o reconhecimento de uma suposta inocência sexual feminina que é constantemente dissimulada pelas próprias meninas: existem aquelas que são também agressivas, aceitam a brincadeira "osada" ou o jogo sexual, gostam de pronunciar palavrões e estão interessadas em saber sobre a sexualidade. As professoras afirmam que elas "lêem revistas sobre sexo" na própria sala de aula às escondidas, falam sobre revistas pornográficas vistas em casa, e gostam de brincar agarradas com os machos e bater nos colegas (ainda que sejam menos que os meninos).

\section{Brincadeira e "sacanagem" x Tabu da sexualidade}

Nesta seção, mostrarei como as representações normativas e medicalizantes sobre a sexualidade infantil estão presentes no cotidiano es- 
colar, entre as docentes. Adotarei a perspectiva analítica de Michel Foucault (1988), quando o autor afirma que as instituições da modernidade intensificaram a veiculação da linguagem sobre o corpo e o sexo como estratégia discursiva de poder nas formas de exercício da sexualidade. Esse poder discursivo é veiculado, por exemplo, pela ordem médica e incorporado por outras instituições, como a escola, na produção de saberes do corpo (Altmann, 2001; Corrêa, 1994).

Dessa forma, os agentes tradicionalmente responsáveis pela socialização e disciplina do corpo parecem confirmar essa tese foucaultiana da produção de discursos sobre a sexualidade como dispositivos de poder e administração corporal (Altmann, 2001; Corrêa, 1994; Louro, 1997). Em Pinaúna, por exemplo, esses discursos apresentam conteúdos variados e muitas vezes desencontrados: a linguagem da "sacanagem”, falada entre os pares da socialização, e aquela que envolve saberes transmitidos das instituições para os sujeitos da socialização. No caso dos grupos aqui estudados, quando veiculada entre as crianças, a sexualidade é percebida, sobretudo nas brincadeiras, como obscenidade, palavrão e nos jogos eróticos com o corpo. É como se a sexualidade estivesse no âmbito da diversão, não merecendo, portanto, atenção especial em conversas com adultos.

De outro modo, quando abordada dentro da sala de aula, a sexualidade recobre-se de sentido associado à procriação ou atividade de reprodução biológica. Uma professora, numa conversa sobre "namoros de criança" diz que fala sobre sexualidade na sala de aula da seguinte forma: "falo sobre as plantas, a reprodução das plantas e dos seres humanos e as crianças dizem espantadas: - O que é isso Pró?!" (Antonieta, 32 anos). Uma outra docente ressalta como os alunos se esquivam do assunto sexualidade no âmbito da sala e comenta a reação, quando em "uma aula sobre sexualidade, aparelho reprodutor, ficaram rindo, não fizeram perguntas. Um aluno de onze anos, crente (protestante) disse: - Minha mãe disse que é muito cedo para aprender essas coisas". As professoras percebem que há um "silêncio" sobre a sexualidade por parte da família e das crianças, mesmo que o assunto seja reprodução humana. Há um tabu para tratar da questão e mesmo quando um agente legítimo da informação (a professora), coloca o tema como pauta da aula, "as crianças não falam nada sobre o corpo, têm vergonha de perguntar; os pais não tocam no assunto, não falam no assunto. O problema é de casa" (Moema, professora). Várias professoras ressaltam o receio de abordar o tema da sexua- lidade na sala de aula, pois sabem que os pais dos alunos também são vigilantes na aprendizagem dos filhos e exigem que a escola mantenha o "silêncio" sobre um assunto que deveria estar na alçada apenas da família. "[...] sinto restrições, receios, pois sei que os pais não gostam que fale sobre sexualidade na escola. Os filhos chegam falando em casa e eles vão pedir satisfações à professora, acham errado despertar a curiosidade das crianças" (Edneuza, professora).

Além dessa dificuldade, a idéia de que as crianças socializam umas às outras e adquirem conhecimento sobre corpo e sexualidade sem a interferência dos pais, ainda causa estranheza, como ilustrado na fala de uma professora da comunidade: "os meninos estão osados, com total liberdade; os pais não disciplinam bem; os meninos já falam de sexo e acabam influenciando as outras crianças, aquelas que os pais são mais rigorosos" (Verena, professora). Paradoxalmente ao que indicam como vigilância da família sobre a educação sexual dada na escola, as professoras normalmente acusam essas mesmas famílias de não exercerem maior controle sobre a sexualidade das crianças, já que permitem aos filhos assistir aos programas de TV considerados inapropriados, além de deixálos livres, o que contribui, segundo elas, para que aprendam coisas sobre sexo com outras pessoas na rua.

A maioria dessas professoras reconhece que as crianças lidam com a sexualidade como objeto de gracejos e piadas. Para uma docente de uma turma de alunos de nove a onze anos de idade, ao falarem de sexualidade, os meninos "levam o sexo pro lado pejorativo, rabiscam (no caderno), levam pro lado da obscenidade, expondo o órgão sexual de forma pejorativa. Explico sobre isso, digo que sexo é natural, tem o tempo certo, que homens e mulheres se relacionam" (Edneuza, 33 anos). Para ilustrar o tratamento galhofeiro com a sexualidade, a mesma docente relata um caso na sala em que " $\mathrm{um}$ menino desenhou na borracha um menino $e$ uma menina; o menino com o pênis introduzido na vagina, e depois foi carimbando no caderno. Expliquei que é natural, não precisa exibir para os colegas. Conversei em particular com os dois. O menino até chorou, pediu desculpas" (Edneuza, professora, sobre alunos da 3ạ série).

As contradições e ambigüidades que envolvem o falar e o não falar sobre sexualidade entre pais e filhos, e o próprio conhecimento infantil sobre o corpo se resumem na entrevista de uma docente que trabalha com alunos de cinco a sete anos de idade: "não percebo nada de sexualidade. Eles não têm ainda essa curiosi- 
dade sobre sexualidade, estão mais pro lado da brincadeira. As crianças que vêm (pra escola) já conhecem o corpo; quando falo do corpo humano já vão falando, sabem distinguir o macho da fêmea; os meninos falam o pinto pra fazer xixi, as meninas é xereca. Os pais não ensinam sobre sexualidade, ainda estão naquele tabu de antigamente, deixam as coisas acontecer. Deixam pra falar mais tarde, quando já estão adolescentes com seus catorze, quinze anos" (Jurema, professora). Ao mesmo tempo em que não percebe qualquer expressão de sexualidade no meio infantil, a professora relata uma situação de sala de aula em que o assunto adquire duplo sentido: "quando trabalho as sílabas $C A, C O, C U$, as crianças não falam, têm vergonha de dizer a sílaba CU, e dizem: - Minha Pró, você está falando osadia e CU não pode falar. Eu digo que pode falar sim, que CU é por onde saem as fezes. As crianças me dizem: - Mas se eu chegar em casa falando $C U$, o papai vai me bater. Eu digo pra eles dizerem aos pais que é por onde as fezes saem" (Jurema, professora).

Nessa situação, parece existir uma confusão generalizada entre o sentido veiculado pelas crianças e a explicação do significado proposto pela professora. Os alunos quando chamam a atenção para a palavra CU, não estão colocando em foco o ânus como parte fisiológica do corpo, mas a conotação sexual e vulgar que o termo assinala. Além disso, podem estar associando a sílaba à expressão muito corriqueira entre eles, quando mandam o colega "tomar no cu", significando uma agressão verbal ao outro, e, simbolicamente, uma relação de força e dominação. A professora é que parece introduzir de forma (in)voluntária outra dimensão erótica da palavra por meio da linguagem coloquial corrente nesse e outros espaços sociais, assim como continua a associar sexualidade com fisiologia humana.

Outra situação em sala de aula, semelhante a uma cena de teatro, com alunos entre sete e treze anos de idade, quando a professora conversava sobre sexualidade: "aí outro dia eu disse assim: - Olhe, menino tem pinto. Ah, quando eu falei que menino tem pinto, foi uma risadaria. Aí eu perguntei: - Vocês entenderam o quê de pinto? O que foi que vocês (suprime a palavra) de pinto? Aí ninguém não explicou né. Aí eu disse, sabe o que acontece de pinto, eu vou explicar pra vocês o que é que acontece de pinto: porque o menino tem pênis, o pênis do menino é comprido, não é comprido onde faz xixi? - O menino faz xixi em pé ou sentado? - Ah, em pé professora. Então, e a menina faz como? Sentada, né isso? Então, porque nós, mulheres, somos diferentes de homens. Homem faz xixi em pé porque não pode sentar e nós mulheres não fazemos xixi em pé, nós mulheres só podemos fazer xixi sentadas, porque da nossa o quê? Diga o quê? - Ah, eu não sei não professora! - Então eu vou explicar; eu tava explicando a eles (diz para a pesquisadora): - Ói, nós temos nossa vagina e os meninos têm os pênis deles; então os meninos têm os pênis que é comprido; e a nossa vagina é comprida? Não. Então, é por isso que nós sentamos no sanitário. Aí depois ficou numa boa (frisa para a pesquisadora). Também não perguntaram mais nada" (Aída, 61 anos de idade).

Nesse relato, a docente frisa que a turma ri com a pronúncia dos termos sexuais e que os alunos se calam na sala, mas em várias situações as crianças demonstram fingir desconhecimento sobre o assunto na presença da professora. Nesse mesmo contexto, ao tentar apontar as diferenças entre homens e mulheres, ela comete várias confusões, a começar pela explicação naturalizante de que os meninos fazem xixi em pé porque não podem sentar no vaso. De outro modo, demonstra desconhecer a anatomia dos órgãos sexuais femininos internos e externos, ao afirmar que as meninas sentam porque a vagina não é comprida, ao contrário dos meninos. Nessa visão, a conformação das genitálias e todo aparato biológico marcariam as diferenças dos comportamentos, essencializando as identidades de gênero e sexuais.

As professoras, portanto, dão explicações sobre as diferenças entre meninos e meninas, naturalizando o comportamento com base na fisiologia e anatomia corporais de homens e mulheres, sem dimensionar outros aspectos, como o cultural e o social.

Numa outra situação, entre alunos de sete a oito anos de idade, outra professora teceu um comentário, referindo-se ao que um menino falou sobre uma colega, reforçando que seu posicionamento foi no sentido de manter o silêncio, já que considera esses meninos muito "osados". O diálogo se sucedeu da seguinte forma: menino: "ah, professora, Fulana tá com uma camisinha no bolso". Professora: "vocês sabem o que é camisinha?”. Turma: “não”. Professora: “já abriram alguma camisinha?”. Turma: “não”. Professora (para a pesquisadora): "não quis explicar porque já são osadinhos demais. Um aluno chegou até a dizer: - Ah, eu já vi na televisão. (E continua) Era bem capaz de dizerem em casa $e$ as mães virem reclamar na escola".

Um aspecto curioso nessas falas é que as professoras deixam transparecer o interesse em manter as crianças ignorantes quanto à sexualidade, com receios de que elas se tornem muito conhecedoras do assunto, além de evitar possíveis reclamações dos pais. Essas posturas 
revelam formas de poder exercidas pela escola no controle do aprendizado da sexualidade das crianças (Louro, 1997), assim como expressam também um desconhecimento e falta de capacitação para trabalhar essas questões, incluindo a dimensão de gênero e a educação sexual no âmbito escolar. Vejamos na abordagem seguinte, como esse tema aparece e é entendido no meio infantil.

\section{As brincadeiras sexuais}

As práticas e representações da sexualidade na comunidade corporificam-se também na sociabilidade infantil, sobretudo nas brincadeiras sexuais realizadas pelas crianças.

Há uma compreensão generalizada da sexualidade como "osadia", como atividades corporais indicativas de obscenidade. Uma expressão muito recorrente, usada pelas crianças para classificar as brincadeiras sexuais é o termo "brincar de osadia". "Brincar de osadia" é um conjunto de jogos em que as crianças, estimuladas eroticamente, usam o corpo umas das outras, ou simplesmente pelo uso de uma linguagem sexual para teatralizar a eroticidade. Assim, retirar a roupa do corpo, baixar as calças, mostrar os órgãos genitais, falar palavrões e xingamentos em grupo, cochichar ao ouvido, etc., sinalizam um tipo de brincadeira "osada". Ressalto que a palavra "osadia”, diferente de ousadia, tem uma carga semântica bastante acentuada, com conotação sexual. Lore e Lorinho, ambos de 9 anos e Maria, de 7 detalham as condutas assim classificadas: Lore: "é pra sentar de perna fechada, pra não brincar com homem, porque eles são osados" (orientação dos pais). Lorinho: "e eu não sou osado, viu?" (Lore ri). Pesquisadora: “o que é homem osado?” Lore: “é porque pega pra ficar fazendo osadia". Lorinho: "pega as menina, vai pra algum beco, pra tá fazendo osadia”. Lore: "não é nada disso. Quando tá brincando de esconde-esconde, aí os meninos começa a ir, aí quando chega lá no escuro, aí começa a dizer assim: eu vou comer gente, eu vou comer gente!" (ri). Lorinho: "é, diz assim mesmo! " Maria: "todo mundo se pica!".

As brincadeiras sexuais são realizadas normalmente por iniciativa dos meninos, ainda que várias meninas participem dessas práticas, sendo discriminadas pelas colegas, que as evitam e impedem que compartilhem os mesmos jogos. Essas representações masculinas servem como referência para comparar o comportamento feminino, caracterizado pelos atributos de ingenuidade, passividade, desinteresse pela sexualidade, inocência e vergonha sexual, o que contradiz muitas falas das próprias crianças e práticas no dia-a-dia. É o caso de uma garota que entre várias outras, não aceita as provocações dos colegas, segundo relato de duas meninas: "quando algum menino mexe com Vanessa, ela responde com palavrões”. Dizem que se um garoto gritar: "Vanessa sua horrorosa!" Ela retruca: “horrorosa é tu que lambe verme do meu cu. Cara feia pra mim é fome, pegue o cu, frite e come". Resumindo a imagem da colega, as duas dizem que "tudo dela é cu". (Jamira, 9 anos; Iasmina, 10 anos). Outro exemplo é a fala de um garoto entre um grupo de amigos: "as meninas brincam de boneca, de casa, de namorar (risos). É brincar de casinha, de pai e mãe: aí tem dois namorados, aí tem a filha pequena, aí a mãe e o pai não gostam... Aí tem quatro meninos e quatro meninas, aí o mais velho e a mais velha das mulé, das meninas é o pai mais a mãe; aí os menor é filho; aí tem madrinha, tem padrinho. Aí fica brincando, aí faz um tipo de casa assim, aí fica beijando, namorando... Aí pode namorar, pode beijar, pode até ficar na cama se deixar" (Jailson, 13 anos).

O espaço da praia é outro lugar onde estão essas representações de gênero. Grupos de meninos na faixa etária de 7 a 14 anos de idade a freqüentam para o banho de mar e a prática de vários jogos com bola. Enquanto se banham no mar, gostam de tirar as roupas e expor as genitálias, fazem vários gracejos e travessuras, como correr atrás de um colega na água tentando enfiar-lhe um pedaço de pau (ou qualquer objeto pontiagudo). Nesses vários jogos, existem regras de separação entre as crianças. O distanciamento entre os grupos por sexo se mantém por meio das brincadeiras em que os meninos provocam as meninas, usando o artifício da agressão verbal e comportamento galhofeiro nos momentos em que tentam tocá-las em suas partes íntimas, sob o olhar e gargalhadas dos colegas. Iasmina, 10 anos, mencionara uma situação concreta em que "o menino falou que queria que a menina fosse pra praia pra dar um chupão nela. Ficam pegando nas meninas na praia". As meninas comumente mencionam os convites feitos pelos garotos para inseri-las em alguns de seus jogos, ao que elas interpretam como sendo uma forma grosseira de exibição de masculinidade daqueles considerados "osados".

Os garotos se divertem com a "manipulação" da sexualidade deles e das meninas. Entrevistando um grupo de meninos de 8 a 13 anos de idade, na praia, depois de um jogo de bola com os pés, eles fazem referência às classificações relativas às meninas: "tem aquelas assanhadas, que quando o menino bole, elas ficam dando risada. As direitas dão porrada, ta- 
pa ou faz queixa aos pais" (Marcos, 13 anos). As que aceitam o jogo são categoricamente enquadradas: "na praia mesmo tem aquelas assanhadas, que quando os meninos enfiam o dedo, passam a mão por baixo da água, elas ficam dando risada" (Renani, 12 anos). "Ontem mesmo eu passei a mão em uma na água (mar) e ela ficou rindo" (Caca, 8 anos). Ao contrário dessa reação, a expectativa é para que as meninas não aceitem as investidas: "os meninos ficam fazendo osadia e elas gostam” (Cláudio, 11 anos). Assim, os garotos afirmam sua virilidade e condição de macho, contrastam as meninas "decentes" das "indecentes" pelo grau de aceitação à brincadeira ou jogo erótico. Nas representações masculinas, a mulher não pode expressar desejo, e quando isso acontece, são estigmatizadas por terem interesses sexuais tais quais os homens têm na vida diária.

A idéia de perigo no contato entre meninos e meninas é constantemente divulgada na comunidade para as crianças a partir dos sete anos de idade e, sobretudo, para os jovens de maiores idades. Meninas e meninos se evitam principalmente nos jogos que envolvem o corpo, receosos das fofocas feitas pelos adultos que podem pôr em dúvida a masculinidade, bem como o comportamento esperado das garotas. Um grupo de meninos, entre 11 e 13 anos, estando na praia, falam da preocupação em corresponder às expectativas dos adultos, tanto homens como mulheres, quanto à sua virilidade. Dizem que os pais reclamam quando estão brincando com meninas e são repreendidos: Mimo: "ah, você só fica brincando com as meninas... fica brincando de se esconder". Pesquisadora: "por que os pais reclamam?" Mimo: (explica um fato concreto) "Tinha mais meninas e só tinha eu de homem. Não querem (os pais) que eu fique brincando com as meninas". [Um colega do grupo explica melhor]: Marcos: "se tiver só ele de menino no meio (das meninas), pensa que tá namorando, brincando de osadia”. Pesquisadora: “o que é osadia?". Marcos: "é baixar a roupa! (Todos riem). Elas deixam”. Buia: “não sei disso não, viu!”. Lula: “antigamente, quando a gente brincava com as meninas, agora a gente...”. Marcos: “eu não brinco com menina na água (na praia) não”. Pesquisadora: “por que?". Marcos: "porque não, eu não gosto não, porque vão dizer mal de mim. Falam que é bitoca..., viado, pit bicha".

Nesse caso, a pressão sobre os meninos vem de duas formas: ele pode ser considerado como "osado" por se interessar pelas garotas ou também pode ser visto como homossexual, por andar no meio de meninas. Assim, a possibilidade de ser visto como "viado", entendido como o menino que gosta de andar nos grupos de meninas, ou que se deixa tocar eroticamente por outro garoto, pode expor a imagem negativa dele como homem: ao invés de machão, ativo, dominador, viril, é acionado o estereótipo de menino passivo sexualmente, que é usado eroticamente pelos colegas e que se interessa pelos “assuntos de menina”. Num grupo de meninos de 8 a 11 anos de idade, perguntados sobre o que sabiam sobre sexualidade, ficaram rindo, enquanto um toma coragem e declara que "os meninos maiores ficam pegando os menores para fazer osadia, fazer de mulher, puta".

Por meio das representações de gênero, imputam-se valores na mente e corpo das crianças, de forma que nos jogos sexuais se joga também com a perda de virilidade, poder e moral social (Duque-Arrazola, 1997). Essas representações e práticas engendram corpos sexualizados marcados pelo gênero, produzindo e reproduzindo socialmente os corpos masculinizados e feminilizados.

\section{Considerações finais}

Como mostra essa etnografia, as crianças se interessam por questões sexuais, articulam linguagens e práticas sobre a sexualidade por meio de jogos sexuais apreendidos nos variados espaços de sociabilidade. Nesse contexto de pesquisa, sexualidade é entendida por meninos e meninas como "osadia", termo que conota atrevimento, obscenidade, brincadeira erótica e, sobretudo, tem sentido sexual. A “osadia" representaria a sexualidade em seu aspecto mais amplo, expressando prazer e fantasias com o corpo, diferente de sua dimensão normativa/reprodutiva. Isso fica evidente nas contraditórias práticas e discursos de docentes e crianças no cotidiano de Pinaúna.

Em geral, as professoras naturalizam a sexualidade e as representações sobre o corpo como mecanismo controlador dos comportamentos das crianças, por meio de discursos supostamente científico-biológicos associados à reprodução, anatomia e fisiologia humanas. A questão, no entanto, é que meninos e meninas parecem reconhecer duas ordens de discursos sobre a sexualidade: o da norma, disciplinador e medicalizante, e outro da criação fantasiosa, das brincadeiras erotizadas, da "sacanagem", da "osadia". Essas duas concepções se chocam no processo de socialização da pessoa e da própria construção da sexualidade, pois, em relação a esta, as crianças aprendem na rua, com os colegas, nas revistas, na televisão, enquanto a escola só reconhece legitimidade no 
discurso médico/normalizador, moralizante e institucionalizado. Dessa forma, as professoras reconhecem que meninos e meninas têm conhecimentos sobre sexo e erotismo, mas preferem o "silêncio" e o tolhimento. A escola e a sala de aula viram palcos da normalização sexual, compactuando com a família algumas ordens discursivas da sexualidade.

\section{Agradecimentos}

Artigo originado de investigação com bolsa pelo Programa Interinstitucional de Pesquisa em Metodologia de Pesquisa em Gênero, Sexualidade e Saúde Reprodutiva, financiada pela Fundação Ford, Instituto de Medicina Social (Universidade do Estado do Rio de Janeiro), Instituto de Saúde Coletiva (Universidade Federal da Bahia) e Núcleo de Estudos de População (Universidade Estadual de Campinas), instituições e pessoas às quais sou inteiramente grata pelo apoio e valiosíssimas orientações. A pesquisa contou com a orientação das professoras Cecília McCallum e Maria Luiza Heilborn.

\section{Referências}

ALTMANN, H., 2001. Orientação sexual nos parâmetros curriculares nacionais. Estudos Feministas, 9:575-585

CORRÊA, M., 1994. Medicalização social e a construção da sexualidade. In: Aids e Sexualidade. O Ponto de Vista das Ciências Humanas (M. A. Loyola, org.), pp. 117-140, Rio de Janeiro: Universidade do Estado do Rio de Janeiro/Relume Dumará.

EPSTEIN, D., 1999. Sex play: Romantic significations, sexism and silences in the schoolyard. In: A Dangerous Knowing: Sexuality, Pedagogy and Popular Culture (D. Epstein \& J. Sears, ed.), pp. 25-42, London/New York: Cassel.

FOUCAULT, M., 1988. História da Sexualidade I: A Vontade de Saber. 10a Ed. Rio de Janeiro: Edições Graal.

HEILBORN, M. L., 1999. Construção de si, gênero e sexualidade. In: Sexualidade: O Olhar das Ciências Sociais (M. L. Heilborn, org.), pp. 40-58, Rio de Janeiro: Jorge Zahar.

LOURO, G. L., 1997. Gênero, Sexualidade e Educação. Uma Perspectiva Pós-estruturalista. 5ạ Ed. Rio de Janeiro: Vozes.

LOYOLA, M. A., 1999. A sexualidade como objeto de estudo das ciências sociais. In: Sexualidade: O Olhar das Ciências Sociais (M. L. Heilborn, org.), pp. 3139, Rio de Janeiro: Jorge Zahar.
Ainda sobre as representações de gênero na comunidade, há também um protótipo hegemônico de masculinidade, que é exercido pelos meninos "osados" e aquele da feminilidade inocente e dessexualizada, ainda que outras formas de construção de gênero estejam presentes, colocando em constante tensão e invertendo os padrões existentes, como os meninos “não-osados", estudiosos, não-violentos, e as meninas "osadas", agressivas e interessadas na sexualidade.
DUQUE-ARRAZOLA, L. S., 1997. O cotidiano sexuado de meninos e meninas em situação de pobreza. In: Quem Mandou Nascer Mulher? Estudos sobre Crianças e Adolescentes Pobres no Brasil (F. R. Madeira, org.), pp. 343-402, Rio de Janeiro: Record/ Rosa dos Tempos.

MALINOWSKI, B., 1982. A Vida Sexual dos Selvagens do Noroeste da Melanésia: Descrição Etnográfica do Namoro, do Casamento e da Vida de Família entre os Nativos das Ilhas Trobriand. Rio de Janeiro: Francisco Alves.

MEAD, M., 1971. Macho e Fêmea. Um Estudo dos Sexos num Mundo em Transformação. Rio de Janeiro: Vozes.

PARKER, R., 1991. Corpos, Prazeres e Paixões. A Cultura Sexual no Brasil Contemporâneo. São Paulo: Best Seller.

SCHIEFFELIN, B. B., 1990. The Give and Take of Everyday Life. Language Socialization of Kaluli Children. Cambridge University Press.

WEEKS, J., 1999. O corpo e a sexualidade. In: O Corpo Educado: Pedagogias da Sexualidade (G. Louro, org.), pp. 35-82, Belo Horizonte: Autêntica.

Recebido em 9 de junho de 2003

Versão final reapresentada em 25 de setembro de 2003 Aprovado em 22 de outubro de 2003 